\title{
A New Spectrophotometric Method for the Estimation of Almotriptan Malate in Tablets Using Metol - Cr (VI) Reagent
}

\author{
Buridi Kalyana Ramu' ${ }^{1 *}$, G Rupa Kumari² and M Syam bab ${ }^{3}$ \\ ${ }^{1}$ Department of Chemistry, Maharajah's College (Aided and Autonomous), Vizianagaram, Andhra Pradesh, India \\ ${ }^{2}$ Department of Technical Education, MRAGR Govt. Polytechnic, Vizianagaram, Andhra Pradesh, India \\ ${ }^{3}$ Department of Organic Chemistry and Analysis of Foods Drugs and Water Laboratories, Andhra University, Visakhapatnam, Andhra Pradesh, \\ India
}

*Corresponding Author: Buridi Kalyana Ramu, Department of Chemistry, Maharajah's College (Aided and Autonomous), Vizianagaram (AP), India.

Received: September 16, 2019; Published: September 26, 2019

DOI: $10.31080 /$ ASPS.2019.03.0403

\begin{abstract}
A simple and sensitive visible spectrophotometric method has been developed for the estimation of almotriptan malate either in bulk or tablet dosage forms. The method involves charge-transfer complex formation at $\mathrm{pH} 3.0$ with $\mathrm{p}-\mathrm{N}$ methyl benzoquinone monoimine (in situ oxidation product of metol and oxidant $\mathrm{Cr}(\mathrm{VI})$ to form a purple colored species with an absorption maximum of $540 \mathrm{~nm}$. Beer's law obeyed in the concentration range of 20-100 $\mu \mathrm{g} / \mathrm{ml}$. No interference was observed from the usually existing additives in pharmaceutical formulations and the applicability of the method was examined by analyzing AXERT tablets containing AM. The statistical data indicates the accuracy, reproducibility and the precision of the proposed method.

Keywords: Beer's Law; Charge-Transfer Complex Formation; Regression Equation; Statistical Analysis; Tablets
\end{abstract}

\section{Introduction}

Almotriptan malate (AM) (Figure 1) is a selective and potent serotonin 5-hydroxy trytamine1B/1D (5-HT 1B/1D) receptor agonist. It is chemically designated as $1[[[3-[2-($ Di methyl amine) ethyl]-1H-indol-5-yl] methyl] sulfonyl] pyrrolidine \pm - hydroxy butanedioate [1] (1:1). Its empirical formula is $\mathrm{C}_{17} \mathrm{H}_{25} \mathrm{~N}_{3} \mathrm{O}_{2} \mathrm{~S}_{4} \mathrm{C}_{4} \mathrm{H}_{6} \mathrm{O}_{5}$ representing molecular weight of 469.56 . It is a white to slightly yellow crystalline powder that is soluble in water and sparingly soluble in methanol. Almotriptan is available in market as conventional tablets (AXERT).The drug is absorbed well orally, with an absolute bioavailability of around $70 \%$. The drug is used to treat severe migraine headaches and vascular headaches; acute treatment of migraine attacks with or without aura. The drug binds with high affinity to 5-HT 1D, 5-HT 1B and 5-HT 1F receptors. Because of the particular distribution of the 5-HT 1B/1D receptors, almotriptan basically constricts the human meningeal arteries; therefore it has a limited effect on arteries supplying blood to the brain and little effect on cardiac and pulmonary vessels. Ameliorate migraine through selective constriction of certain intracranial blood vessels, inhibition of neuro peptide release and reduced transmission in trigeminal pain pathway.

In literature, several analytical methods such as HPLC [2-5], HPTLC [6], HPLC-MS/MS [7], LC-ESI-MS/MS [8], UV Spectrometric

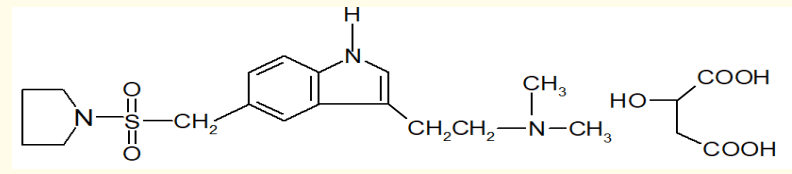

Figure 1: Chemical structure of Almotriptan malate.

[9,10], Fluorometric and Coloricmetric [11], visible spectrophotometric [12-16] have been reported for the determination of AM in biological fluids and formulations. For routine analysis, simple, rapid and cost effective visible spectrophotometric methods are useful and preferred in small scale pharmaceutical industries. Nevertheless, there still exists a need for development of sensitive accurate and flexible visible spectrophotometric method for the determination of AM in pharmaceutical preparations and quality control analysis.

Metol is a versatile chromogenic reagent capable of reacting with different functional groups, enabling the estimation of many pharmacodynamic agents belonging to different classes [17-19]. So the authors have made some attempts in this direction and succeeded in developing a method. The proposed method is based on an observation that metol gives purple color with the drug at PH 3.0 
in the presence of an oxidant $\mathrm{Cr}(\mathrm{VI})$ under specified experimental conditions.

The proposed method for AM determination has many advantages over other analytical methods due to its rapidity, normal cost and environmental safety. Unlike HPLC, HPTLC procedures, the instrument is simple and is not costly. Economically, all the analytical reagents are inexpensive and available in any analytical laboratory. The method can be extended for the routine quality control analysis of pharmaceutical products containing AM.

\section{Materials and Methods (Experimental)}

Apparatus and chemicals

A Milton Roy UV/Visible spectrophotometer model-1201 with $10 \mathrm{~mm}$ matched quartz cells was used for all spectral measurements. A Systronics digital pH meter mode-361 was used for $\mathrm{pH}$ measurements. All the chemicals used were of analytical grade. AXERT tablets procured from Ortho Mc Nell Pharmaceuticals, USA.

PMAP (metol) solution (Wilson labs, 0.2\%, 5.80x10-3M): prepared by dissolving $200 \mathrm{mg}$ of $\mathrm{P}-\mathrm{N}$-methyl amino phenol sulphate in $100 \mathrm{ml}$ of distilled water, Potassium dichromate solution (BDH $0.01 \mathrm{M}$ ) was prepared in the usual way. H 3.0 Buffer solution: Prepared by adding $500 \mathrm{ml}$ of potassium acid phthalate solution $(0.2 \mathrm{M}$; $40.546 \mathrm{~g}$ in 1lit.water) to $408 \mathrm{ml}$ of $0.1 \mathrm{M} \mathrm{HCl}$ and the volume of mixture was brought to 2 lit. with distilled water and $\mathrm{pH}$ was adjusted to 3.0 .

\section{Preparation of standard drug stock solution}

An accurately weighed quantity of $50 \mathrm{mg}$ pure AM drug was dissolved in little amount of acetic acid and made to $50 \mathrm{ml}$ with distilled water. The prepared stock solution was stored at $4^{0} \mathrm{C}$ protected from light. This stock standard solution was further diluted stepwise with distilled water to obtain working standard solution and a series of standards were freshly prepared during the analysis day.

\section{Determination of wavelength maximum $\left(\lambda_{\max }\right)$}

A $5.0 \mathrm{ml}$ portion of the working standard solution of AM $(500 \mu \mathrm{g} /$ $\mathrm{ml}$ ) was accurate measured into $25 \mathrm{ml}$ calibrated tube. $15 \mathrm{ml} \mathrm{pH} 3.0$ buffer solution, $1.0 \mathrm{ml}$ of $0.2 \%$ metol solution and $1.0 \mathrm{ml}$ of $0.01 \mathrm{M}$ $\mathrm{K}_{2} \mathrm{Cr}_{2} \mathrm{O}_{7}$ solution were added and mixed thoroughly. The solution was diluted to the mark with distilled water. In order to investigate the wavelength maximum, the above solution was scanned in the range of $350-750 \mathrm{~nm}$ by UV-Visible spectrophotometer. From the spectra (Figure 2), it was concluded that $540 \mathrm{~nm}$ is the most appropriate wavelength for analyzing AM with suitable sensitivity.

\section{Analysis of Bulk samples}

Aliquots of the standard AM drug solution $((1.0-5.0 \mathrm{ml}, 500 \mu \mathrm{g} /$ $\mathrm{ml}$ ) were transferred into a series of $25 \mathrm{ml}$ calibrated tubes. $15 \mathrm{ml}$ of pH 3.0 buffer solution $1.0 \mathrm{ml}$ of $0.2 \%$ metol solution and $1.0 \mathrm{ml}$

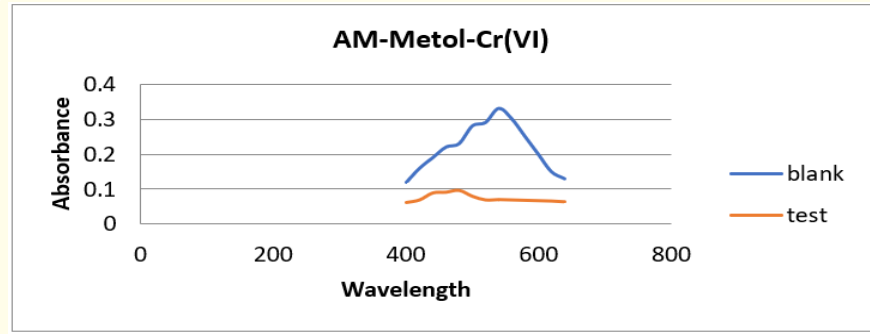

Figure 2: Absorption spectra of AM-metol-Cr (VI) system.

of $0.01 \mathrm{M} \mathrm{K} 2 \mathrm{Cr} 2 \mathrm{O} 7$ solution were added and mixed thoroughly. The solution was diluted to the mark with distilled water and the absorbance were measured at $540 \mathrm{~nm}$ against a reagent blank prepared omitting drug solution in a similar manner during the stability period of $5 \mathrm{~min}-2 \mathrm{hr}$. The amount of drug in a sample was calculated from its calibration curve (Figure 3 ).

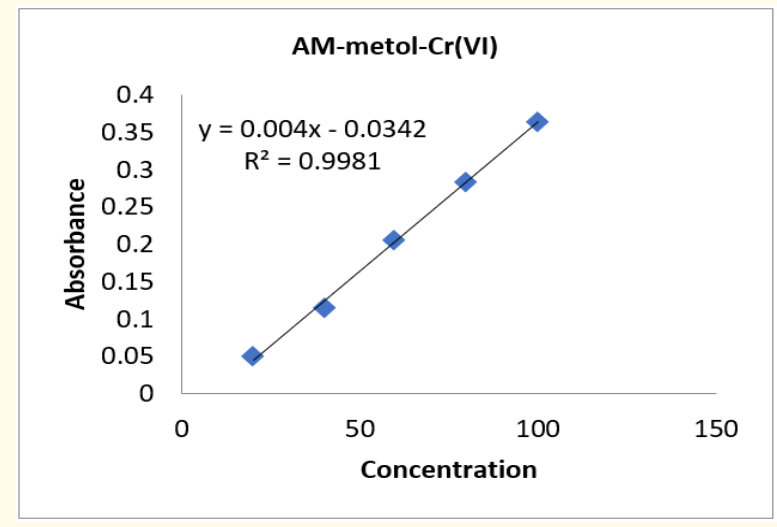

Figure 3: Beer's Law plot of AM-Metol-Cr (VI) system.

\section{Analysis of tablets}

Twenty tablets were weighed accurately and powdered and an amount of the tablet powder equivalent to $10 \mathrm{mg}$ of AM drug was treated with $8.0 \mathrm{ml}$ of glacial acetic acid (warmed on a boiling water-bath for $5 \mathrm{~min}$ with occasional shaking). The solution was cooled to room temperature, filtered and made up to $10 \mathrm{ml}$ with distilled water to give a solution of $1 \mathrm{mg} / \mathrm{ml}$. This stock standard solution was further diluted stepwise with distilled water to obtain working standard solution and was analyzed as described in the analysis of bulk samples.

\section{Results and Discussion}

The optimum conditions for the development of the method was established by varying the parameters one at a time and keeping the others fixed and observing the effect produced on the absorbance of the colored species. Maintaining the $\mathrm{pH}$ of the solution at $3.0 \pm 0.1$ was found to be the best for attaining the maximum sensitivity. Use of 1.0 -2.0 ml of PMAP (metol) solution and 1.0 -2.0 $\mathrm{ml}$ of $0.01 \mathrm{M} \mathrm{K}_{2} \mathrm{Cr}_{2} \mathrm{O}_{7}$ solution afforded the maximum absorbance 
values. A waiting period of 1-3 min was necessary between the additions of PMAP and $\mathrm{K}_{2} \mathrm{Cr}_{2} \mathrm{O}_{7}$ solutions for the generation of $\mathrm{p}$ $\mathrm{N}$-methyl benzoquinone monoimine (PMBQMI) by the action of $\mathrm{K}_{2} \mathrm{Cr}_{2} \mathrm{O}_{7}$ on PMAP. Prolonging the waiting period beyond 3 min resulted in low absorbance values, probably owing to the partial hydrolysis of the PMBQMI formed in situ to the quinone state. Among the water miscible solvents examined, water was found to be the best for final dilution of the solution. Maximum color intensity was attained within $10 \mathrm{~min}$ after the final dilution and remained stable up to $1 \mathrm{hr}$. The optical characteristics such as Beer's law limit, Sandell's sensitivity, molar absorptivity, percent relative standard deviation (calculated from the six measurements containing $3 / 4^{\text {th }}$ of the amount of the upper Beer's law limits ) were calculated and the results are summarized in Table-1. Regression characteristics like standard deviation of slope (Sb), standard deviation of intercept (Sa), standard error of estimation (Se) and \% range of error $(0.05$ and 0.01 confidence limits) were calculated and are shown in table 1.

AXERT tablets containing AM were successfully analyzed by the proposed method. The values obtained by the proposed and reference methods for formulations were compared statistically by the t-and F-test and found not to differ significantly. As an additional demonstration of accuracy, recovery experiments were performed by adding a fixed amount $(10 \mathrm{mg})$ of the drug to the pre analyzed formulations at three different concentration levels. These results are summarized in table 2 . The interference studies in the determination of AM in pharmaceutical formulation revealed that the

\begin{tabular}{|l|c|}
\hline \multicolumn{1}{|c|}{ Parameter } & Values \\
\hline$\lambda_{\max }(\mathrm{nm})$ & 540 \\
\hline Beer's law limit $(\mu \mathrm{g} / \mathrm{ml})$ & $20-100$ \\
\hline Sandell's sensitivity $\left(\mu \mathrm{g} / \mathrm{cm}^{2} / 0.001\right.$ abs. unit & 0.011594203 \\
\hline Molar absorptivity $(\mathrm{Litre} / \mathrm{mole} / \mathrm{cm})$ & 40499.55 \\
Correlation Coefficient & 0.998 \\
\hline Regression equation $(\mathrm{Y})$ & \\
\hline Intercept $(\mathrm{a})$ & -0.038 \\
\hline Slope(b) & 0.004 \\
\hline \%RSD** & 1.35 \\
\hline \% Range of errors & \\
\hline 95\% Confidence limits) & 1.414 \\
\hline 0.05 significance level & 2.218 \\
\hline 0.01 significance level & \\
\hline
\end{tabular}

Table 1: Optical characteristics, precision and accuracy of proposed method.

$* \mathrm{Y}=\mathrm{a}+\mathrm{bx}$, where $\mathrm{Y}$ is the absorbance and $\mathrm{x}$ is the concentration of $\mathrm{AM}$ in $\mu \mathrm{g} / \mathrm{ml}$

${ }^{* *}$ calculated from six determinations

normally existing excipients and additives like starch, talc, stearic acid, boric acid, gelatin, magnesium carbonate and sodium lauryl sulphate were found not to interfere even when present in excess (1-100 folds). However, preliminary clean up procedure with $\mathrm{CHCl}_{3}$ is necessary prior to the estimation of AM in formulations if lactose is present.

\begin{tabular}{|c|c|c|c|c|c|c|c|}
\hline \multirow[b]{2}{*}{ Method } & \multirow[b]{2}{*}{ *Formulations } & \multirow{2}{*}{$\begin{array}{c}\text { Labeled } \\
\text { Amount (mg) }\end{array}$} & \multicolumn{3}{|c|}{ Found by Proposed Method } & \multirow{2}{*}{$\begin{array}{c}\text { Found by } \\
\text { Reference } \\
\text { Method } \pm \text { SD }\end{array}$} & \multirow{2}{*}{$\begin{array}{l}\# \% \text { Recovery } \\
\text { by Proposed } \\
\text { Method } \pm \text { SD }\end{array}$} \\
\hline & & & $\begin{array}{l}* * A m o u n t \\
\text { found } \pm \text { SD }\end{array}$ & $\mathbf{t}$ & $\mathbf{F}$ & & \\
\hline AM-metol-Cr(VI) & Tablet-1 & 12.5 & $12.43 \pm 0.16$ & 1.32 & 3.37 & $12.44 \pm 0.15$ & $98.42 \pm 1.25$ \\
\hline
\end{tabular}

Table 2: Analysis of almotriptan malate in tablets.

*Tablet- 1 AXERT tablets of Ortho Mc Nell Pharmaceuticals, USA

${ }^{* *}$ Average \pm Standard deviation of six determinations, the $\mathrm{t}$ - and $\mathrm{f}$-values refer to comparison of the proposed method with UV reference method. Theoretical values at $95 \%$ confidence limits $\mathrm{t}=2.57$ and $\mathrm{F}=5.05$.

\#Recovery of $10 \mathrm{mg}$ added to the pre analyzed sample (average of three determinations).

Reference method (reported UV method) using methanol $\left(\lambda_{\max }=227 \mathrm{~nm}\right)$.

\section{Chemistry of colored species}

The cyclic imino group in indole portion of drug AM is involved in the formation of a colored species with situ oxidized form PMBQMI obtained from PMAP-Cr (VI). The probable sequences of reactions in two steps based on analogy are presented in figure 4.

\section{Conclusion}

The reagents utilized in the proposed method are normal cost, readily available and the procedure does not involve any critical reaction conditions or tedious sample preparation. The proposed method possesses reasonable precision, accuracy and is simple, sensitive and can be used as alternative method to the reported 


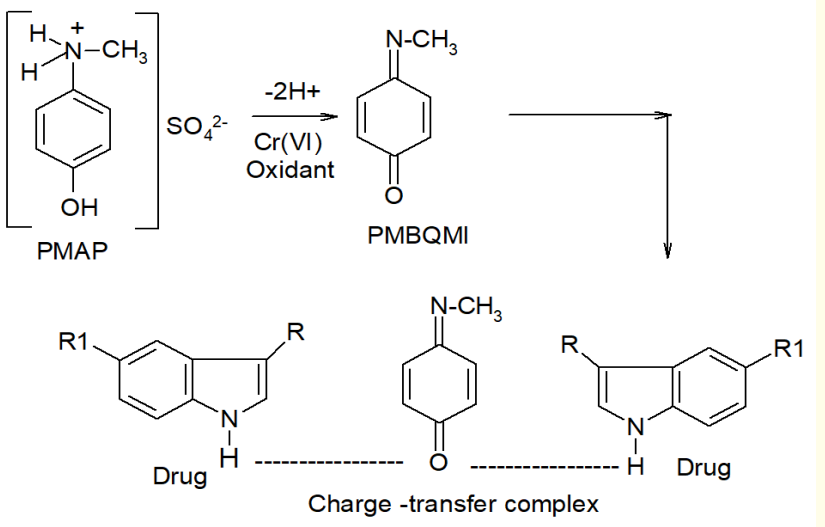

Figure 4: Probable sequence reactions of the proposed method.

\section{Acknowledgments}

The authors (BK Ramu and MS Bab) are thanks to the University Grants Commission, New Delhi for providing financial assistance under Teacher fellowship and also thanks to University authorities for providing facilities in this work.

\section{Bibliography}

1. JON Maryadele. The Merck Index 14th ed., Merck and Co Inc., New Jersey (2006).

2. A Suneetha and B Syamsundar. "A validated RP-HPLC method for estimation of almotriptan malate in pharmaceutical dosage form". Journal of the Chinese Chemical society 57 (2010): 1067-1070.

3. AP Kumar., et al. "A validated RP-HPLC method for determination of process related impurities in almotriptan malate API". Journal of Pharmaceutical and Biomedical Analysis 46 (2008): 792-798.

4. Phani kumar V and Sunandamma Y. "New RP - HPLC method development and validation for analysis of almotriptan". International Journal of Pharmaceutical Chemistry 1 (2011): 542545.

5. Petikam Lavudu., et al. "Development and Validation of HPLC Method for The Determination of Almotriptan Malate in Bulk and Tablet Dosage Forms". International Journal of PharmTech Research 5 (2013): 459-466.

6. A Suneetha and B Syamsundar. "Development and validation of HPTLC method for the estimation of almotriptan malate in tablet dosage form". Indian Journal of Pharmaceutical Sciences 72 (2010): 629-632.

7. K Ravi kumar., et al. "Method development and validation of almotriptan malate in human plasma by HPLC-tandem mass spectrophotometry: Application to pharmacokinetic study". Scientia Pharmaceutica 80 (2010): 367-378.
8. R Nageshwar Rao., et al. "LC_ESI-MS/MS determination of in vivo metabolites of almotriptan malate in rat plasma, urine and feces: application to pharmokinetics". Journal of Chromatography B Analytical Technol Biomedical Life Sciences (2012): 891892: 44-51.

9. A Suneetha and B Syamsundar. "New simple UV spectrophotometric method for estimation of almotriptan malate in bulk and pharmaceutical dosage form". Asian journal of Research in Chemistry 3 (2010): 142-144.

10. Suneetha A., et al. "Spectrophotometric estimation of almotriptan malate in bulk and pharmaceuitical formulations by Multivariate Technique". International Journal of Medical Chemistry and Analysis 2.2 (2012): 76-80.

11. EI-Bagary Ramzia., et al. "Fluorimetric and colorimetric methods for the determination of some anti-migraine drugs". Journal of Chemical and Pharmaceutical Research 3.4 (2011): 304-314.

12. Viplava Prasad U., et al. "Visible spectrophotometric analysis of almotriptan malate bulk and formulations". International Journal of Scientific and Technology Research 1 (2011): 86-89.

13. Viplava Prasad U., et al. "Development of New Visible Spectrophotometric Methods for Quantitative Determination of Almotriptan Malate as An Active Pharmaceutical Ingredient In Formulations". International Journal of Drug Development and Research 4 (2012): 369-374.

14. Viplava Prasad U., et al. "Development of New Visible Spectrophotometric Methods for Quantitative Determination of Almotriptan Malate Using Quinones as Chromogenic Reagents". Chemical Science Transactions 1 (2012): 297-302.

15. Viplava Prasad U., et al. "Quantitative assay of almotriptan malate in pure drug and pharmaceutical preparations using simple and convenient visible spectrophotometric method". International Journal of Pharma Sciences and Research 3.5 (2012): 379-386.

16. K Prabhavthi., et al. "A simple spectrophotometric assay ofalmotripta Malate in builk and pharmaceutical formulations". World Journal Pharmaceutical research 5 (2016): 747-753.

17. CSP Sastry., et al. Indian Drugs (1984): 145.

18. M N Reddy., et al. Indian Journal of Pharmaceutical Sciences 53 (1991): 219.

19. M Krishnamurthy and U Murali Krishna. Indian Drugs 22 (1985): 171.

Volume 3 Issue 10 October 2019 (C) All rights are reserved by Buridi Kalyana Ramu., et al. 